The authors cannot enter into correspondence concerning the implementation of similar systems.

\section{Acknowledgements}

Thanks to the CLUES team: Joe Jackson (head nurse), David Ozanne and Jane Elson (managers), Bernie Gray (medical records) and Nigel Rogers and Roy Clements (IT). special articles
*Geoff Searle Consultant Psychiatrist, NBCMHT, Turbary Park Centre, Turbary Park Avenue, Bournemouth BH11 8SR

(e-mail: geoff.searle@dorsethc-tr.swest.nhs.uk), Tomasz Rynkowski,

Andrew Sephton, Daniel Pickford, Geoff O'Neill The Business School,

Bournemouth University, Talbot Campus, Fern Barrow, Poole BH12 5BB

Psychiatric Bulletin (2002), 26, 148-151

ISABEL C. BURGESS

\title{
Service innovations: attention-deficit hyperactivity disorder - development of a multi-professional integrated care pathway
}

\author{
AIMS AND METHOD \\ There is a need for multi-disciplinary \\ input into the diagnosis and \\ management of attention-deficit \\ hyperactivity disorder (ADHD). \\ We describe the development of a \\ multi-professional integrated care \\ pathway incorporating education, \\ community paediatrics, child and \\ adolescent mental health services \\ and general practice.
}

\author{
RESULTS \\ Using parent-held documentation \\ this pathway forms the basis of a \\ community-based ADHD clinic.
}

\begin{abstract}
CLINICAL IMPLICATIONS
A training programme for schools and health professionals raises awareness of the features of ADHD and covers appropriate management within schools.
\end{abstract}

Attention-deficit hyperactivity disorder (ADHD) is a neurobehavioural disorder affecting $0.5-1 \%$ of British school children (Taylor \& Hemsley 1995). The affected child often has difficulty learning, giving rise to special educational needs that, combined with poor peer and family relationships, can lead to lack of self-esteem (American Psychiatric Association, 1994). ADHD is commonly associated with other developmental disorders, such as speech and language delay or specific learning difficulties, and with conduct disorder or oppositional defiant disorder (American Psychiatric Association, 1994).

When a diagnosis of ADHD is considered, assessment should include an interview with the parents as well as direct consultation with the school (American Academy of Pediatrics, 2000). The diagnosis should only be made when the child meets the DSM-IV (American Psychiatric Association, 1994) criteria, and the evaluation should include assessment for comorbid conditions.

Not all children with ADHD will need stimulant medication and a number may be managed solely with behavioural interventions (Hill, 1998). Direct comparison of stimulant medication with behavioural interventions suggests that the former is relatively more effective (Miller et al, 1998), however the combination of behavioural management plus medication offers greater power than behavioural management alone (MTA Cooperative Group, 1999). The addition of medication to behavioural treatments is clinically effective and relatively cost effective (Lord \& Paisley, 2000). Thus, if the response to behavioural methods is insufficient, a trial of medication should be considered. Treatment should be initiated by child and adolescent psychiatrists or paediatricians with expertise in ADHD, although continued prescribing may be performed by general practitioners (GPs) under shared-care guidelines. Children receiving medication should receive regular monitoring (National Institute for Clinical Excellence, 2000).

Much has been made of the need for more integrated working between the different professional groups involved in the care of children, particularly in the arena of child mental health (Graham, 2000). ADHD, with its effect on all aspects of a child's life, but particularly on education and learning, lends itself well to this approach. There is a need for cooperation among the different professional disciplines, and for more joint working between child and adolescent mental health services (CAMHS) and paediatric services. Community paediatricians, with their close working relationships with schools and expertise in developmental paediatrics, are ideally placed for this role.

\section{Background}

In mid-Cheshire a multi-professional team for ADHD was established in August 1999, jointly funded by the Cheshire Community Healthcare Trust and the Cheshire 
Education Authority. The remit was to address diagnosis and management of children with ADHD within health and education services and to establish a protocol for multi-agency working. The team consists of a staff grade community paediatrician, a school nurse, an educational psychologist and a school teacher.

Previously, children suspected of having ADHD were assessed by one of two local child psychiatrists or by one of five hospital-based consultant paediatricians. Follow-up of children on medication for ADHD was either by CAMHS, hospital paediatricians or by local GPs alone.

\section{Audit}

An initial baseline audit identified the number of children locally with ADHD and established existing practice in diagnosis and management, identifying potential areas for intervention. This led to the formation of a multi-professional integrated care pathway for ADHD.

The audit identified 112 school-aged children in the area treated for ADHD, a prevalence of $0.24 \%$. Given the reported prevalence of $0.5-1.0 \%$, this would suggest that up to 230 local children with ADHD are unidentified. Eighty-seven per cent had been diagnosed by a child psychiatrist and $13 \%$ by a hospital paediatrician, with only $55 \%$ having consulted school as part of the assessment process. Behavioural issues were addressed as part of management in $71 \%$ of cases. Thirteen per cent of children receiving medication were no longer under specialist care, and were reviewed only by their GP.

This identified the need to raise awareness of ADHD locally in order to identify those still undiagnosed. We needed to standardise the assessment process, to ensure that schools are consulted as part of diagnosis, and to ensure that behavioural management is implemented before considering medication. We felt that follow-up care of children receiving medication should be addressed to ensure adequate specialist supervision.

\section{Integrated care pathway}

A multi-professional group met to develop an integrated care pathway (Campbell et al, 1998) for ADHD. This group comprised the four team members, representatives from community paediatrics, acute paediatrics, child and adolescent psychiatry, general practice, education, social services, pharmacy and the audit department. The pathway was based on recommendations from the Royal College of Psychiatrists (Joughin \& Zwi, 1999), and on European Guidelines (Taylor et al, 1998).

The pathway forms the documentation for a new community-based ADHD clinic. The clinic covers all school-age children, except those with moderate or severe learning difficulties. Our referral form, which lists the core symptoms of ADHD, is sent initially to the community paediatrician with responsibility for that particular child's school. They perform a vision check, audiogram and developmental screen to rule out problems in these areas causing the difficulties with behaviour or attention. They liaise with the school to identify any problems within the school setting, and the teacher completes a questionnaire, comprising a rating scale (Goyette et al, 1978) and questions on academic progress, peer relationships, behaviour and concentration. This information is forwarded with the referral form. Parents also complete a rating scale (Goyette et al, 1978).

The clinic is run by the community paediatrician and school nurse, and is based in a local clinic. The initial assessment part of the pathway records presenting symptoms, past medical history, birth and neonatal details and family and social information. Physical examination includes noting any dysmorphic features, cardiovascular examination, and assessment of motor skills, including coordination. Growth parameters are recorded on a growth chart (Child Growth Foundation, 1996), and blood pressure is recorded alongside age-specific reference values. There is a check-list for the common comorbidities of ADHD, with referral pathways for any problems identified (speech and language therapy referral for language delay, physiotherapy referral for dyspraxia and referral to school for specific learning difficulties). The information collected is considered along with the school questionnaire in order to reach a diagnosis. The DSM-IV criteria are listed and must be met for the diagnosis of ADHD to be made.

If the DSM-IV criteria are clearly not met, the child leaves the pathway. If the behavioural difficulties are not severe the child is referred back to his/her schoolbased community paediatrician for support, otherwise he/she may be referred on to CAMHS for assessment (see Fig. 1 for pathway).

If after initial assessment the diagnosis is not clearcut, or there are significant psychiatric comorbidities (conduct disorder, anxiety), the child is referred via the pathway to the child psychiatrist for further assessment.

If the DSM-IV criteria are met the clinic offers behaviour management as the initial intervention. This is a twofold approach - the child and parents work with the clinic nurse to address behaviour within the home and other social settings, while the school is informed of the diagnosis and reminded of the training and interventions for schools that are offered by the team (described below). Thus the teacher is able to implement appropriate behavioural strategies in school. Information about ADHD is made available to the parents and child, including a list of parent support groups.

After implementing behavioural strategies the child is reviewed, and if these interventions alone are insufficient, he/she may be referred via the pathway to the child psychiatrist for review and consideration of a trial of medication. Possible contraindications to medication are excluded, and if the trial is to proceed, the school is informed and asked to give feedback on the effects of medication. A questionnaire and rating scale is sent to the school to assess the effect of medication or behavioural interventions.

Once medication is stabilised, follow-up reverts to the community clinic, with four monthly monitoring of growth and blood pressure, and annual full blood counts. The pathway contains guidelines for 


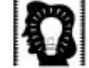

special articles
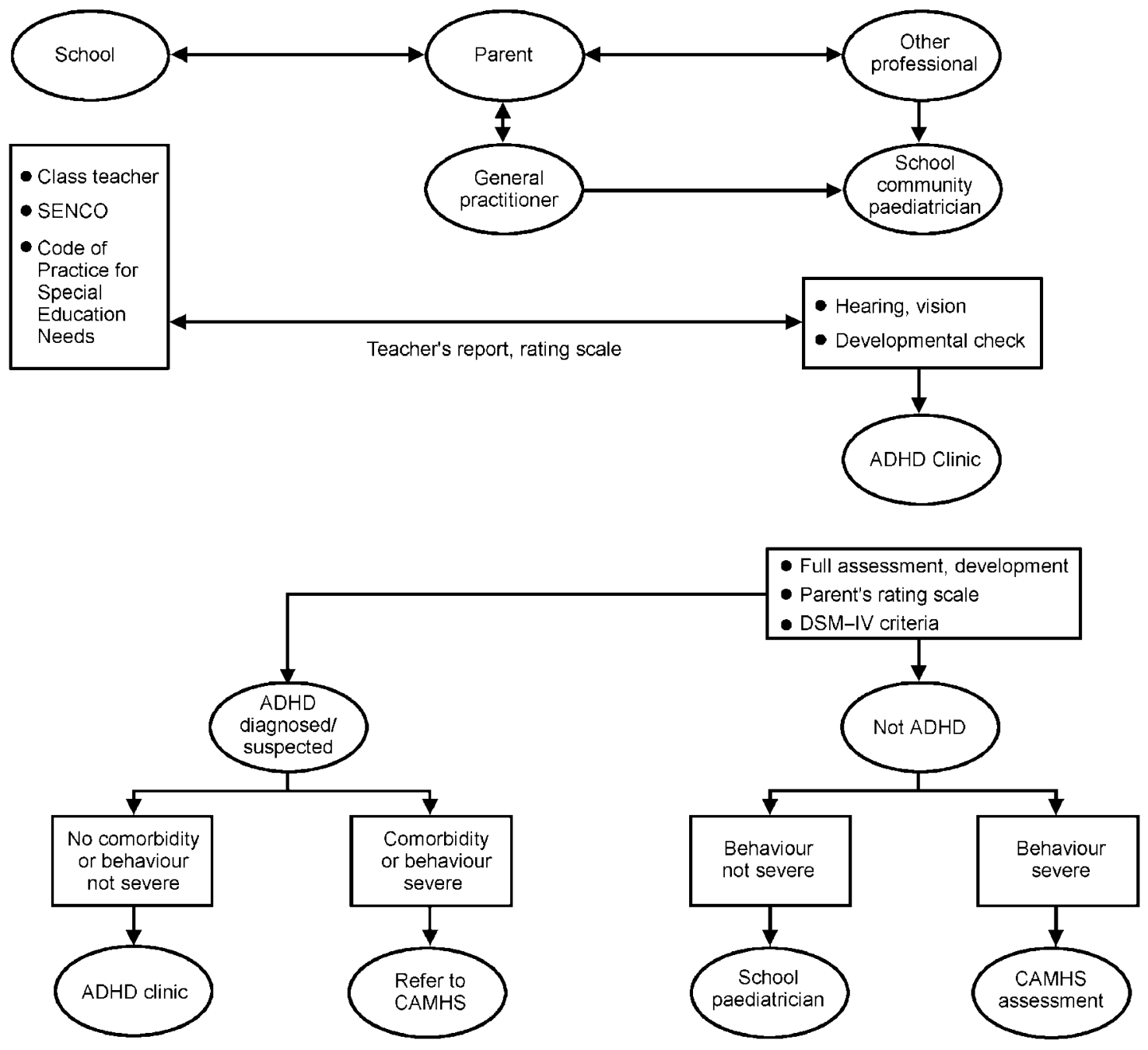

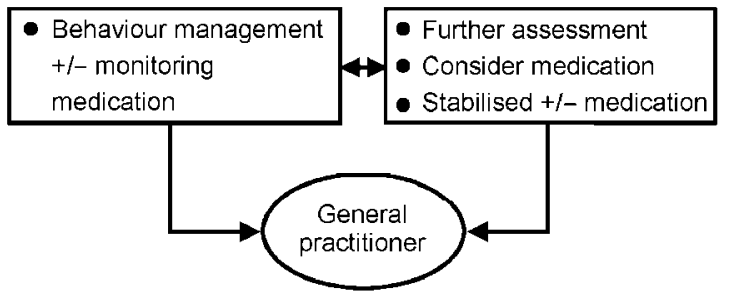

Repeat

prescribing

Fig. 1. Overview of the pathway re-referral back to the child psychiatrist, for example if side-effects of medication occur. In addition each child is reviewed annually by the child psychiatrist in accordance with local guidelines. GPs provide repeat prescriptions and the pathway contains a tear-out slip that the parent hands to the GP, confirming the dose of medication and that all necessary monitoring and review has occurred. GPs agree not to prescribe without this information. This system avoids any delay in issuing prescriptions, and ensures that children receiving medication are reviewed appropriately.

\section{Record keeping}

All documentation, including the community clinic, psychiatric review, parent and school questionnaires, and growth chart, is contained in a parent-held record. Each sheet is carbon-copied, with copies for the community paediatric and psychiatric notes, to avoid duplication of note-taking. This parent-held record facilitates communication between all the professionals involved with the child, both medical and educational, and allows the parents access to the information recorded. 


\section{Educational interventions}

The team has established a training programme for professionals, which has been offered to every local school, as well as health and social services groups. This gives background information and awareness of the features of ADHD and guidelines for the safe storage and administration of medication within schools. The sessions also cover classroom management strategies to support learning and behaviour for children with ADHD, within the framework of the Code of Practice for Special Educational Needs (Department of Education, 1994). An information pack covers the course content, as well as additional educational resources.

Where particular difficulties in school are identified, the team educational psychologist or teacher may offer individual interventions to the school, in conjunction with the school's educational psychologist or learning support service staff.

\section{Evaluation}

Each pathway contains an audit sheet that completes the audit cycle, allowing the clinic and pathway to be evaluated and, where necessary, improved. A parent satisfaction questionnaire assesses the pathway in relation to the previous system of assessment and diagnosis.

\section{Conclusion}

Integrated care pathways are often applied to acute conditions in hospital settings, for a single episode of care. We have developed a community-based integrated care pathway, which is used in a number of different out-patient settings and by a number of different professionals within education and health. By using parent-held documentation all the recorded information is available to each professional that sees the child. Communication between different professionals is enhanced, and the diagnostic process is made more transparent.

Development of the integrated care pathway has enhanced cooperation between the different professional disciplines, particularly community paediatrics, CAMHS, and education, and given a better understanding of the role that each can play in the management not only of ADHD but also of the comorbid conditions commonly encountered.

Completion of the audit cycle will monitor adherence to the pathway, and will allow evaluation of the changes introduced, and modification of the pathway where appropriate in line with current evidence.

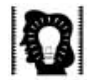

special articles

\section{Acknowledgements}

The author wishes to thank Gill Hide, Linda Caldecott and Margaret Watkins (ADHD team members), Dr Janet Llewelyn for suggesting an integrated pathway and supporting its development and $\mathrm{Dr} \mathrm{H}$. Kat for his support, training and advice and for evaluating the manuscript.

\section{References}

AMERICAN ACADEMY OF PEDIATRICS (2000) Clinical practice guideline: diagnosis and evaluation of the child with attention-deficit/hyperactivity disorder. Pediatrics, 105, 1158-1169.

AMERICAN PSYCHIATRIC

ASSOCIATION (1994) Diagnostic and Statistical Manual of Mental Disorders (4th edn) (DSM-IV). Washington, DC: APA

CAMPBELL, H., HOTCHKISS, R., BRADSHAW, N., et al (1998) Integrated care pathways. BMJ, 316, 133-137.

CHILD GROWTH FOUNDATION (1996) Boys Growth Chart (birth-18 years) Girls Growth Chart (birth -18 years). London: Child Growth Foundation.

DEPARTMENT OF EDUCATION (1994) Code of Practice of Special Educational Needs. London: Central Office of Information.

GOYETTE, C., CONNERS, C. \& ULRICH, R. (1978) Normative data on revised Conners parent and teacher rating scales. Journal of Abnormal Child Psychology, 6, 216-236.

GRAHAM, P. (2000) Mental health must be "centre stage" in child welfare. Archives of Disease in Childhood, $\mathbf{8 3}$ 4-6.

HILL, P. (1998) Attention deficit hyperactivity disorder. Archives of Disease in Childhood, 79, 381-385.

JOUGHIN, C. \& ZWI, M. (eds) (1999) FOCUS on the Use of Stimulants in Children with Attention-Deficit Hyperactivity Disorder. London: Royal College of Psychiatrists CRU.

Isabel Burgess Staff Grade Community Paediatrician, Department of Community Paediatrics, Cheshire Community HealthcareTrust, Wharton Primary Healthcare Centre, Crook Lane, Wharton, Winsford, Cheshire CW7 8GY
LORD, J. \& PAISLEY, S. (2000) The Clinical Effectiveness and CostEffectiveness of Methylphenidate for Hyperactivity in Childhood. Version 2. London: National Institute for Clinical Excellence.

MILLER, A., LEE, S., RAINA, P., et al (1998) A review of Therapies for Attention-Deficit/hyperactivity Disorder. Canadian Coordinating Office for HealthTechnology Assessment (CCOHTA).

MTA COOPERATIVE GROUP (1999) A 14-month randomized clinical trial of treatment strategies for attention-deficit/hyperactivity disorder. Archives of General Psychiatry, 56, 1073-1086.

NATIONAL INSTITUTE FOR CLINICAL EXCELLENCE (2000) Guidance on the use of Methylphenidate (Ritalin Equasym) for Attention Deficit/ Hyperactivity Disorder (ADHD) in Childhood. London: NICE.

TAYLOR, E. \& HEMSLEY, R. (1995) Treating hyperkinetic disorders in childhood. BMJ, 310, 1617-1618.

—, SERGEANT, J., DOEPFNER, M. et al (1998) Clinical guidelines for hyperkinetic disorder. European society for child and adolescent psychiatry. European Child and Adolescent Psychiatry, 7(4), 184-200. 